\title{
O DRAGÃO VAI AO MAR: A EXPANSÃO NAVAL CHINESA E SUAS IMPLICAÇÕES ESTRATÉGICAS ${ }^{1}$
}

\author{
THE DRAGON GOES TO THE SEA: CHINA'S NAVAL EXPANSION AND ITS \\ STRATEGIC IMPLICATIONS
}

DOI: $10.5380 /$ cg.v10i1. 78759

\author{
Leonardo Coelho Assunção Santa Rita²
}

\begin{abstract}
Resumo
Desde a segunda década do século XXI, a República Popular da China vem se destacando cada vez mais como uma potência marítima em ascensão. O objetivo principal deste artigo é discutir atentamente o processo de expansão e modernização das forças navais da China e a relação que esse processo tem com alguns importantes objetivos políticos do país. Serão avaliadas, primeiramente, aquelas iniciativas dedicadas à formação de uma marinha com capacidade de projeção de força além-mar (Blue Water Navy) e em seguida serão trabalhadas as capacidades A2/AD (Anti-Access/Area-Denial), bem como as forças não convencionais de law enforcement marítimo. Por fim, serão discutidas as motivações político/estratégicas que estão empurrando uma conhecida potência continental para o mar. Para realizar essa tarefa, será mobilizada a bibliografia especializada bem como os dados acerca das forças navais chinesas para identificar as tendências de mudança.
\end{abstract}

Palavras-chave: China; Blue Water Navy; Estratégia Naval; A2/AD; Rota da Seda Marítima.

\begin{abstract}
Since the second decade of the 21st Century, the People's Republic of China has increasingly stood out as a rising maritime power. The main goal of this article is to carefully discuss the process of expansion and modernization of China's naval forces and the relation that this process has with important policy objectives of the country. Firstly, those initiatives dedicated to the formation of a navy with overseas force projection capabilities (Blue Water Navy) will be evaluated, followed by A2/D2 (Anti-Access/Area-Denial) capabilities, as well as the non-conventional maritime law enforcement forces. Finally, the political and strategic motivations that are pushing a well-known continental power to the sea will be discussed. To accomplish this task, specialized literature will be used as well as data about Chinese naval forces to identify changing trends.
\end{abstract}

Keywords: China; Blue Water Navy; Naval Strategy; A2/AD; Maritime Silk Road.

\section{INTRODUÇÃO}

A República Popular da China quase sempre foi tratada como uma grande potência terrestre e continental. Essa percepção acerca do país asiático se deve a diversos fatores de natureza

\footnotetext{
${ }^{1}$ Este artigo está licenciado sob a Licença Creative Commons Attribution (CC BY 4.0), sendo permitido o compartilhamento com reconhecimento da autoria e publicação inicial nesta revista.

${ }^{2}$ Mestrando no Programa de Pós-Graduação em Relações Internacionais da Pontifícia Universidade Católica de Minas Gerais e egresso do curso de Relações Internacionais da Pontifícia Universidade Católica de Minas Gerais. E-mail: leonardocasr29@gmail.com. ORCID: https://orcid.org/0000-0003-2282-2235.
} 
geográfica, social e política. Primeiramente, a China é um dos países com a maior área territorial do globo, com um território que se estende do Nordeste ao Sudeste asiático e da Ásia Central ao Extremo Oriente. Os chineses também são os mais numerosos do mundo, com uma população que ultrapassa mais de 1,3 bilhão de pessoas (CIA, 2020). Essa percepção se deve também a algumas características político/ideológicas da China. A ideologia Maoísta, propagada e defendida pelo Partido Comunista Chinês, dava ênfase às massas proletárias como principal meio de transformação social, o que levou, gradativamente, ao favorecimento do exército e das forças terrestres em detrimento das demais. Por último, algumas demandas de natureza estratégica também guiaram essa visão da China como potência exclusivamente continental, já que as principais ameaças e problemas de segurança do país estavam relacionados, principalmente, a questões de integração territorial e disputas fronteiriças.

Todavia, recentemente, essa percepção da China como potência única e exclusivamente continental tem se alterado gradativamente. A partir do século XXI, e sobretudo depois de sua segunda década, a China tem se tornado cada vez mais ativa nos oceanos, tanto como protagonista no comércio quanto como pivô de disputas marítimas. Os chineses também têm mostrado sua vontade cada vez mais pujante de ir ao mar, pelo ritmo de sua expansão naval. Nos dias atuais, a China é o país que mais produz e comissiona navios de guerra no mundo, desde porta-aviões até navios de patrulha costeira. O objetivo principal deste texto é identificar as principais características dessa expansão naval chinesa e as implicações políticas e estratégicas que estão relacionadas com essa postura do país asiático.

\section{O CAMINHO PARA UMA BLUE WATER NAVY}

A primeira coisa que se imagina quando o tema é expansão naval é a modernização e fortalecimento da marinha. No contexto militar chinês, desde que o Partido Comunista Chinês (PCC) detém o poder em Pequim, um grande privilégio e centralidade foi dado ao exército, tanto que até mesmo na nomenclatura as outras forças singulares aparecem como submetidas ao exército, já que a marinha chinesa, por exemplo, se chama Marinha do Exército de Libertação Popular (PLAN)3. Essa situação privilegiada do exército se deve à duas razões principais, uma de ordem político/social e outra de ordem ideológica. A primeira razão é que o exército chinês - e as forças armadas em um contexto mais amplo - possui sua lealdade dedicada primeiro ao PCC e só depois ao povo da China, o que torna o exército um importante instrumento de controle social e de garantia do status quo político (HEILMANN, 2017). Já a razão de natureza ideológica se refere, principalmente, à herança socialista/maoísta, que sustenta que as massas proletárias, e apenas elas, são capazes de vencer e de perder as guerras. Isso significa que a China não precisaria de grandes navios, modernos aviões ou

3 Sigla em inglês para People’s Liberation Army Navy. 
armamentos nucleares para se sobressair nos conflitos, apenas de um grande exército constituído pelo povo chinês (LEWIS, 2014).

Esse cenário começou a mudar em meados dos anos 1990, em um dos grandes processos de abertura da China, e mais recentemente a partir de 2013, com a ascensão de Xi Jinping ao poder. Desde que assumiu o comando do país, Xi vem buscando modernizar e profissionalizar suas forças armadas, além de repaginar as relações entre os militares, o partido e a sociedade (BITZINGER; CHAR, 2019). Essa mudança de postura pode ser observada tanto no aspecto institucional, com o governo de Pequim criando novos organismos e foros ad hoc de segurança e defesa, quanto no aspecto do planejamento de forças, com as mudanças significativas nas áreas/regiões militares e diminuição no pessoal ativo do exército. O objetivo da administração Xi inclui profissionalizar as forças armadas e obter um salto qualitativo, ao mesmo tempo em que reforça a lealdade dos militares ao partido (HEILMANN, 2017).

No que se refere especificamente à PLAN, grande parte do salto qualitativo buscado pela administração Xi Jinping passa pela formação de uma marinha capaz de projetar forças além-mar, o que é conhecido na literatura como Blue Water Navy. Quando se fala em Blue Water Navy, falase, principalmente, de embarcações principais com grande autonomia, capacidade de operar longe da costa e de levar poder de fogo a longas distâncias. Atualmente, o suprassumo de uma marinha com capacidade de projeção de força ${ }^{4}$ além-mar são os grandes porta-aviões ${ }^{5}$, todavia os grandes destroieres e cruzadores de mísseis guiados, os submarinos - sobretudo aqueles movidos à energia nuclear - e navios principais de assalto anfíbio ${ }^{6}$ também são necessários para uma Blue Water Navy (MACHAFFIE, 2020).

O primeiro indício dessa expansão naval chinesa pode ser observado na crescente capacidade do país na área de construção naval. Segundo dados de 2018 fornecidos pela UNCTAD, a China já tinha ultrapassado a Coreia do Sul como o maior construtor mundial de navios, dominando cerca de 40\% do mercado mundial (UNCTAD, 2018). O que chama atenção, muito mais do que a dominância chinesa na indústria naval, é a velocidade com que a China produz e comissiona embarcações. Segundo Childs e Waldwyn (2018), entre os anos de 2014 e 2018 a China comissionou mais navios de guerra em sua marinha - entre submarinos e navios de superfície - do que a mesma quantidade dessas mesmas embarcações servindo nas marinhas da Alemanha, Índia, Espanha, Taiwan e Reino Unido (CHILDS; WALDWYN, 2018). Nesse ritmo de produção e comissionamento, a China chegará

\footnotetext{
4 Nesse caso, especificamente, se refere à projeção de força militar.

5 São porta-aviões movidos à propulsão nuclear e com catapulta para o lançamento de aeronaves.

6 Atualmente, cada marinha possui especificações próprias para definir o tipo de uma embarcação, variando em função do tamanho e da missão. As fragatas e corvetas são embarcações menores utilizadas para defesa e patrulha costeira, sendo que a fragata é, geralmente, maior do que a corveta. Já os destróieres e cruzadores possuem um porte maior e são dedicados a missões de maior alcance, podendo realizar uma série de missões, desde ataque ao solo até antiaérea e antissubmarino. Já os navios de ataque anfíbio são dedicados ao apoio de operações anfíbias como tomada de praias e portos e podem ter ou não aeronaves de asa fixa ou helicópteros.
} 
em 2030 ao impressionante número de 425 navios de guerra, consolidando ainda mais a sua posição como a maior marinha do Pacífico Asiático (CSIS, 2020).

Especificamente no que concerne à formação de uma Blue Water Navy, a China tem dado importantes passos no caminho para a formação de uma força naval com capacidade de projeção de força além-mar. Em 2012, a PLAN comissionou o seu primeiro porta-aviões, o Liaoning (Tipo-001), uma embarcação originalmente pertencente à classe soviética Kusnetsov, que foi comprada da Ucrânia em 1998 e posteriormente reformado e modernizado (CSIS, 2020b). O Tipo-001 é uma embarcação bem mais modesta perto dos porta-aviões estadunidenses da classe Nimitz e Gerald Ford $^{7}$, com um deslocamento de 60 mil toneladas e rampa em vez de catapultas para o lançamento das aeronaves, fator que limita bastante a ação dos caças. O Liaoning tem capacidade para até 24 caças J-15, uma versão chinesa da aeronave de quarta geração russa Sukhoi Su-33. A marinha chinesa também comissionou, em dezembro 2019, o seu segundo porta-aviões, o Shandong (Tipoo01A), modelo muito semelhante ao Liaoning, porém com o destaque de que foi inteiramente construído na China, o que significa um importante passo para a indústria bélica naval chinesa (CSIS, 2019).

Quando o tema é porta-aviões, a China ainda possui um longo caminho a percorrer, visto que esse tipo de embarcação possui um custo elevado de fabricação e manutenção, além de ser bastante complexo de operar, exigindo uma vasta gama de embarcações de escolta e manutenção, o conhecido Carrier Strike Group. Contudo, a PLAN parece disposta a encarar o desafio de operar um número significativo de porta-aviões, com, pelo menos, duas novas classes já encaminhadas. A primeira delas, e que já teve sua construção iniciada em 2018, é o Tipo-002, uma embarcação que virá com catapultas eletromagnéticas para o lançamento de aeronaves e deslocará aproximadamente algo entre 80 e 85 mil toneladas. A segunda classe, e mais ambiciosa, é o Tipo-003 que, além de possuir catapultas eletromagnéticas, deslocará algo entre 90 e 100 mil toneladas e será movido à energia nuclear colocando-o próximo à classe Nimitz da marinha dos EUA (O’ROURKE, 2020).

Para garantir a operação plena dos porta-aviões, a PLAN precisa estar munida de navios de superfície, como destroieres e cruzadores, para a formação de um Carrier Strike Group. ${ }^{8}$ Desde 2013 - período que coincide com a ascensão de Xi Jinping ao poder - até 2019, a marinha chinesa comissionou 19 destroieres, 5 deles apenas no ano de 2017, com destaque para as modernas classes Tipo-052D e Tipo-055 (CSIS, 2020). A classe Tipo-052D é uma moderna embarcação que entrou em serviço em 2014, que desloca cerca de 7,5 mil toneladas e é munida com lançadores verticais de mísseis. A classe Tipo-055 é a mais moderna de todas na marinha chinesa - com a primeira embarcação sendo comissionada em 2019 - e é capaz de deslocar algo entre 10 e 13 mil toneladas, o

\footnotetext{
7 O Gerald Ford possui capacidade de deslocamento de até 110 mil toneladas.

8 Essa necessidade advém do fato de que, sozinho, o porta-aviões não possui sistemas defensivos o suficiente para garantir sua proteção.
} 
que faz com que muitos classifiquem esse navio não como um destróier, mas sim como um cruzador ${ }^{9}$ (O’ROURKE, 2020).

Outro elemento fundamental no Strike Group de um porta-aviões e que é também muito importante para a constituição de uma Blue Water Navy são os submarinos, especialmente aqueles movidos à energia nuclear. Apesar de moderna, a frota de submarinos nucleares chinesa ainda é modesta, com a PLAN operando 10 embarcações, sendo 6 delas submarinos de ataque (SSN) e 4 submarinos lançadores de mísseis balísticos (SSBN). Esses últimos, inclusive, são parte da força de dissuasão nuclear e não atuam em missões de patrulha ou escolta (IISS, 2020). Todavia, vale ressaltar que a força de submarinos chinesa está em rápida modernização, com as embarcações mais antigas e ultrapassadas sendo descomissionadas e substituídas por modelos mais modernos e exclusivamente nacionais ${ }^{10}$, o que mostra que a PLAN está preocupada não apenas com o número de embarcações, mas também com o aspecto qualitativo (O’ROURKE, 2020).

Outro tipo de embarcação essencial para uma marinha capaz de projeção de força além-mar, mas que a China ainda possui uma força muito incipiente, são os navios principais de assalto anfíbio. A principal embarcação operada pela PLAN é o Tipo-071, um navio que se desloca por volta de 20 mil toneladas, possui capacidade para operar 4 helicópteros e transporta até 800 fuzileiros e seus respectivos equipamentos (IISS, 2020). Contudo, a mais ambiciosa de todas essas embarcações é, sem dúvida, o porta-helicópteros de assalto anfíbio Tipo-075, um navio que desloca cerca de 35 mil toneladas e consegue operar até 28 helicópteros, o que o torna bem próximo à classe Wasp operado pelos Marines dos Estados Unidos. Vale ressaltar também que o Tipo-075 ainda está em fase de testes pela PLAN, todavia a construção de mais navios dessa classe já está em andamento, com mais três embarcações na fila (O’ROURKE, 2020).

Esses grandes navios de assalto anfíbio, embora comissionados junto à marinha de seus respectivos países, geralmente são operados pelo corpo de fuzileiros navais. A China não possui uma organização tão robusta e independente como o U.S Marine Corps ${ }^{11}$, todavia o Corpo de Fuzileiros Navais da PLAN (PLANMC) está em franca expansão. Em 2018 o PLAMC contava com cerca 15 mil militares no serviço ativo, já em 2020 esse número chegou na casa dos 25 mil, com o objetivo de chegar a 30 mil até 2025 (IISS, 2020). Segundo o Departamento de Defesa dos EUA (2019), o PLANMC, embora ainda muito subordinado à marinha chinesa, já possui um comando próprio a partir do qual desenvolve e aprofunda as capacidades de ação como força expedicionária (US DEPARTAMENT OF DEFENSE, 2019). Algumas fontes relatam, inclusive, que a intenção do comando militar e do próprio presidente Xi Jinping é expandir a PLANMC para 6 brigadas com 100

\footnotetext{
9 Os cruzadores da classe Ticonderoga da Marinha dos EUA, por exemplo, deslocam algo em torno de 10 mil toneladas.

${ }^{10}$ Uma parte importante da frota de submarinos da China era/é composta de embarcações russas.

${ }^{11}$ Embora submetidos ao Departamento da Marinha, os Marines são quase como uma "quarta força" nas forças armadas estadunidenses, dado o seu nível de independência do comando da Marinha.
} 
mil militares ativos, o que parece um pouco exagerado, mas, ao levar-se em conta o ritmo de expansão das forças navais chinesas, esse não é um número impossível (CHAN, 2017).

\section{CAPACIDADES A2/AD}

Embora o crescimento e modernização das embarcações principais seja parte fundamental da expansão da PLAN, não é apenas desse tipo de navio que vive a marinha chinesa. A construção e o comissionamento de modernas fragatas, corvetas e navios de patrulha costeira têm acontecido num ritmo ainda mais impressionante do que dos demais tipos de embarcações, o que mostra que os objetivos da PLAN são mais diversos do que meramente a expansão de sua capacidade além-mar. De acordo com o Departamento de Defesa dos EUA (2019), essas embarcações, juntamente aos seus respectivos armamentos e sensores, permitirão que a China expanda e aprofunde suas capacidades Anti-Access/Area-Denial (A2/AD)12 (US DEPARTAMENT OF DEFENSE, 2019).

O número de fragatas operadas pela marinha chinesa vem se mantendo mais ou menos estável nos últimos 15 anos, girando entre 45 e 55 embarcações, todavia o processo de modernização e a substituição dos modelos antigos por novos navios têm se dado em ritmo acelerado. Desde de 2006, a PLAN comissionou 30 fragatas da classe Jangkai-II (Tipo-054A), uma embarcação moderna que desloca até 4,5 mil toneladas e possui sistemas de lançamento tanto de mísseis antinavio quanto de mísseis antiaéreos (CSIS, 2020). Vale ressaltar que a embarcação também possui uma variante focada na guerra antissubmarina que foi comissionada a partir de 2009 (IISS, 2020). Embora as fragatas chinesas também sejam capazes de executar algumas missões além-mar, elas foram projetadas, principalmente, para executarem missões em águas próximas (GADY, 2017).

Quando se trata de corvetas, a marinha chinesa impressiona bastante no ritmo em que constrói e comissiona tais embarcações. Até meados de 2014, a PLAN não operava nenhum navio desse tipo. Contudo, em 2019, a marinha chinesa já possuía 43 unidades, numa média de aproximadamente 7 embarcações por ano (CSIS, 2020). Só no ano de 2019, por exemplo, a China comissionou o impressionante número de 15 corvetas, uma quantidade maior de navios desse tipo do que aqueles operados pela marinha brasileira ${ }^{13}$. Todas as corvetas da PLAN são das classes Jiangdao I (Tipo-056) e Jiangdao II (Tipo-056A), modernas embarcações equipadas com sistemas de lançamento mísseis antinavio e antiaéreo (IISS, 2020). A principal diferença entre as duas classes é que o Tipo-056A possui uma variante mais dedicada à guerra antissubmarina (CSIS, 2020)

\footnotetext{
${ }_{12} \mathrm{~A} 2 / \mathrm{AD}$, ou anti-access/area-denial, está relacionado à capacidade de negar a outrem a utilização de um espaço, seja ele terrestre, marítimo ou aéreo (MASTRO, 2014).

13 A marinha brasileira foi utilizada para comparação em função do fato de que as corvetas desempenham um papel muito importante nas forças navais do país. A marinha dos EUA, por exemplo, não possui nenhuma corveta em seus quadros, todavia, esse tipo de embarcação não é muito importante para a consecução dos objetivos estadunidenses
} 
Em termos de submarinos diesel-elétricos, assim como no caso das embarcações movidas à energia nuclear, a PLAN não possui um ritmo tão acelerado de construção e comissionamento como no caso dos navios de superfície. Todavia, embora a produção se dê a uma velocidade mais lenta, a marinha chinesa tem tratado de engajar-se, principalmente, na substituição de submarinos soviéticos ultrapassados por embarcações mais modernas, como aponta o Escritório de Inteligência Naval da Marinha dos EUA (ONI, 2020). A força de submarinos da PLAN pode ser considerada, de certa forma, o calcanhar de Aquiles da marinha chinesa, pois mesmo a moderna classe de submarinos diesel-elétricos Tipo-039 ainda depende dos motores fornecidos por companhias alemãs. Isso significa que, mesmo que a PLAN esteja se livrando dos antigos modelos soviéticos, ainda é dependente de tecnologia estrangeira (IISS, 2020).

Para garantir a capacidade $\mathrm{A} 2 / \mathrm{AD}$, os armamentos são tão importantes, ou até mais relevantes, do que as plataformas que eles equipam. Em uma fala ao Congresso dos EUA, o excomandante das forças estadunidenses no Pacífico, almirante Harry Harris, disse que a China possuía a maior e mais diversificada força de mísseis balísticos e de cruzeiro do mundo (BROOKES, 2019). Parte dessa grande força de mísseis equipa boa parte das embarcações chinesas que patrulham as águas próximas. O primeiro destaque vai para o YJ-18, um míssil de cruzeiro antinavio baseado no modelo russo 3M-54E, que possui um alcance de até $540 \mathrm{~km}$ e uma capacidade de levar uma carga de até $300 \mathrm{~kg}$. O grande trunfo desse armamento é sua capacidade supersônica, podendo atingir até Mach 3 em sua velocidade terminal (CSIS, 2020c). Contudo, vale a pena ressaltar que o YJ-18 só equipa algumas das classes de submarinos e os destroieres da classe Tipo-052 e Tipo-055, já que nem todas as embarcações da marinha chinesa possuem capacidade de operar o armamento (IISS, 2020).

Outro importante míssil de cruzeiro antinavio operado pela PLAN é o YJ-83, um míssil com alcance de até $250 \mathrm{~km}$ e capacidade de levar uma carga de até $160 \mathrm{~kg}$. Apesar de não ter a capacidade supersônica do YJ-18, o YJ-83 pode ser operado por uma variedade maior de embarcações, o que o torna um elemento fundamental na ampliação da capacidade de ataque Over-the-Horizon ${ }^{14}$ da PLAN (GORMLEY; ERICKSON; YUAN, 2014). O YJ-83 equipa, principalmente, quase todas as 52 fragatas da marinha chinesa - destaque para a moderna classe Tipo-054 - e equipa também todas as 43 corvetas Tipo-056. O míssil também é operado pelos mais de 60 navios de patrulha costeira da classe Tipo-022, uma embarcação leve e rápida que pode não contribuir para a ampliação da presença naval chinesa além-mar, todavia é um importante incremento na capacidade A2/AD para PLAN, sobretudo se operado a partir de bases em ilhas próximas (IISS, 2020).

É importante lembrar que a capacidade $\mathrm{A} 2 / \mathrm{AD}$ não se limita apenas aos navios e seus respectivos armamentos. A China possui uma variedade de mísseis baseados em terra - e não necessariamente controlados pela PLAN - cuja missão é impedir que embarcações hostis atuem

14 Over-the-Horizon, nesse caso, significa a capacidade de lançar um ataque sem se aproximar muito dos sistemas defensivos do oponente (GLYNN, 2015). 
próximas à costa chinesa. Um desses mísseis é o DF-21D, um míssil balístico antinavio de médio alcance, capaz de atingir alvos a 1,5 mil km, possui ogiva com capacidade MARV ${ }^{15}$ e um CEP ${ }^{16}$ de aproximadamente 20 m (CSIS, 2020d). O DF-21D é conhecido no círculo militar dos EUA como o "matador de porta-aviões", por ser muito difícil de interceptar ao mesmo tempo que seria preciso o suficiente para atingir um porta-aviões no mar. Discute-se bastante se a China teria capacidades de C4ISR ${ }^{17}$ o suficiente para entregar esse nível de precisão em um míssil balístico. Todavia, em alguns testes realizados, constatou-se que o dispositivo conseguiu atingir um alvo no mar mais ou menos do mesmo tamanho de um porta-aviões (ERICKSON, 2013).

Por último, é importante não deixar de mencionar as instalações militares chinesas em águas próximas, sobretudo no Mar da China do Sul. A China tem construído instalações militares a um ritmo acelerado no Mar da China do Sul, mais especificamente, nas ilhas Spratly e Paracel. Nessas instalações são colocadas pistas de pouso e decolagem, pequenos portos, sistemas de radares e sensores diversos, sistemas de lançamento de mísseis antiaéreos e antinavio e depósitos de suprimentos (AMTI, 2017). Essas instalações podem servir como um tipo de "porta-aviões fixos" para a PLAN, podem ser usadas como bases para embarcações menores, bases para lançamentos de mísseis antiaéreos e antinavio e postos avançados para sistemas de ISR $^{18}$.

QUADRO 1. FORÇAS NAVAIS: EUA X CHINA

\begin{tabular}{|l|c|c|c|c|c|c|c|c|c|}
\hline & $S S B N$ & $S S N$ & $S S C$ & Cruzador & Destróier & Fragata & Corveta & Nap & PA \\
\hline EUA & 14 & 53 & 0 & 24 & 67 & 19 & 0 & 32 & 11 \\
\hline China & 4 & 6 & 49 & 1 & 28 & 52 & 43 & 6 & 1 \\
\hline
\end{tabular}

Fonte: Elaboração Própria.

A fim de ilustrar melhor o status atual das forças navais chinesas, o quadro acima contrapõe as capacidades marítimas da China com as capacidades dos Estados Unidos. É perceptível que, em termos de capacidades de projeção de força, os EUA estão bem na frente dos chineses na medida em que a marinha estadunidense goza do privilégio de operar 11 porta-aviões, todos eles devidamente escoltados pelo seu strike-group de destroieres, cruzadores e submarinos a propulsão nuclear. Todavia, vale ressaltar que, primeiramente, não é toda a frota naval dos EUA que está dedicada às operações no Oceano Pacífico, sendo que apenas a Sétima Frota possui base no Pacífico Asiático (THE..., 2020). E segundo, a China possui capacidades bastantes sólidas quando se fala em proteção costeira e de águas próximas que, combinado com os armamentos antinavio, podem impor sérias dificuldades às capacidades de projeção de força dos EUA (IISS, 2020).

${ }_{15}$ Sigla para: Veículo de Reentrada Manobrável (Maneuverable Reentry Vehicle).

${ }^{16}$ Sigla para: Erro Circular provável de um míssil (Circular Error Probable).

${ }_{17}$ Sigla para: Comando, Controle, Comunicação, Computação, Inteligência, Vigilância e Reconhecimento (Command, Control, Communication, Computing, Intelligence, Surveillance and Reconnaissance).

${ }^{18}$ Sigla para: Inteligência, Vigilância e Reconhecimento (Intelligence, Surveillance and Reconnaissance). 


\section{AGINDO NA ZONA CINZA: GUARDA COSTEIRA E MILÍCIA MARÍTIMA}

A expansão naval da China não se limita apenas à marinha e muito menos às forças convencionais. A guarda costeira chinesa e algumas organizações consideradas como uma espécie de milícia do mar engajam-se ativamente em operações de law enforcement em águas próximas (CSIS, 2020c). Essas operações ocorrem, principalmente, no que é conhecido como zona cinza, no qual a China utiliza amplamente mecanismos não convencionais a fim de assegurar seus objetivos. Na zona cinza evita-se a escalada de conflito ao mesmo tempo que se tenta ocultar, muitas vezes, de onde partiu a ação e quais os seus reais objetivos, a fim de dificultar e atrapalhar o tempo de resposta do eventual adversário (BELO,2020). A China emprega sua guarda costeira e as milícias marítimas ligadas a PLAN nessas operações justamente para evitar o comprometimento que a utilização de embarcações da marinha acarretaria. No final, a China quer garantir a consecução dos seus objetivos mais agressivos sem, necessariamente, deflagrar uma resposta à mesma altura e no mesmo tom (GOLDRICK, 2018).

A guarda costeira chinesa é uma das maiores do mundo e recentemente vem passando por um processo de expansão e modernização. Entre os anos de 2012 e 2015, a organização teve o seu orçamento quase dobrado e se tornou a maior guarda costeira da Ásia, ultrapassando o Japão (MORRIS, 2017). A guarda costeira da China opera, atualmente, cerca de 523 embarcações, sendo várias delas antigos navios operados pela PLAN com a capacidade de deslocamento superior a 1 mil toneladas (IISS, 2020). Especificamente no ano de 2013, a guarda costeira passou por uma grande reforma institucional, no qual a organização foi afastada do comando da PLAN, submetida diretamente a cadeia de comando do Conselho de Estado e fundida com outras três organizações que se dedicavam ao law enforcement marítimo. O objetivo da administração Xi Jinping era tanto expandir e modernizar a organização quanto torná-la mais civil e menos militarizada (MORRIS, 2017).

As milícias marítimas chinesas traçam sua origem nas milícias armadas ligadas ao Partido Comunista, que serviam como uma força paralela para o PCC. Atualmente, as milícias possuem uma função um tanto quanto opaca e estão submetidas a uma cadeia de comando bastante confusa. Segundo alguns autores, essas incertezas e imprecisões que muitas vezes estão presentes nas discussões acerca dessas milícias agradam as autoridades chinesas, já que esses se grupos se engajam, principalmente, em operações de zona cinza cuja imprecisão é característica fundamental (KENNEDY; ERICKSON, 2017). Os indivíduos que servem nessas milícias são todos civis, muitos deles inclusive possuem outras profissões, por exemplo, pescadores. Essas pessoas, muitas vezes, realizam operações de law enforcement utilizando seus navios pesqueiros não identificados, porém muito bem armados. É importante mencionar que essas milícias não são completamente amadoras 
e descoladas do aparato policial e militar da China, recebendo treinamento tanto da PLAN quanto da guarda costeira (KENNEDY; ERICKSON, 2017).

Essa atenção chinesa para as operações de zona cinza e para os elementos assimétricos do poder militar se deve, em grande parte, a alguns elementos da cultura estratégica chinesa. Um desses aspectos da cultura estratégica da China é a doutrina da Três Guerras (Three Warfares), que fundamenta a importância de alguns elementos não convencionais da guerra, como a guerra psicológica, a guerra e opinião pública e a guerra legal (Lawfare) (LEE, 2014). Essa noção acerca da guerra e da importância dos elementos não convencionais se tornou mais relevante na comunidade de defesa chinesa a partir da publicação do livro Unrestricted Warfare, no qual os autores Liang e Xiangsui (1999) sistematizam a ideia de que a guerra não estaria restrita apenas aos campos de batalha de outrora. Essa passagem a seguir sintetiza bem a visão de Liang e Xiangsui (1999) acerca do fenômeno da guerra:

(...) o novo conceito de armamentos é uma visão mais ampla sobre armamentos que enxerga como armamentos todos os meios que transcendem a esfera militar, mas que ainda podem ser utilizados em operações de combate. Nessa visão, tudo que pode beneficiar os seres humanos também pode prejudicá-los. Isso quer dizer que não há nada no mundo atualmente que não possa se tornar um armamento, o que requer que nosso entendimento sobre armamentos seja consciente em romper todas as barreiras (LIANG, XIANGSUI, 1999, p. 25, tradução nossa).19

\section{POR QUE O MAR?}

Diante do que foi apresentado, se faz necessário questionar os motivos que levaram a China, uma potência reconhecida por suas forças terrestres, a se lançar ao mar de maneira tão assertiva. Será que existe alguma característica especial nos oceanos que gerou esse impulso nos chineses? Algum tipo de recurso natural que foi descoberto? Apesar de que, de fato, reservas de gás e petróleo tenham sido descobertas em águas próximas à costa chinesa, não foi exatamente isso que levou a China ao mar. A redução da ameaça vinda da terra devido à queda da União Soviética, o enorme crescimento econômico do país, a possibilidade de se tornar uma potência a nível global e a necessidade de consolidação de sua posição regional estão entre os principais fatores que levaram a China a dedicar mais esforços na expansão de suas forças navais.

Na medida em que a economia da China se expandiu e continua se expandindo, o comércio internacional - principalmente o comércio marítimo - se tornou cada vez mais importante para o crescimento econômico de um país que depende da exportação da sua produção industrial e da

\footnotetext{
${ }^{19}$ No original: "This is because the new concept of weapons is a view of weapons in the broad sense, which views as weapons all means which transcend the military realm but which can still be used in combat operations. In its eyes, everything that can benefit mankind can also harm him. This is to say that there is nothing in the world today that cannot become a weapon, and this requires that our understanding of weapons must have an awareness that breaks through all boundaries" (LIANG, XIANGSUI, 1999, p. 25).
} 
importação de recursos naturais básicos. Segundo um relatório da Organização Mundial do Comércio (OMC), a China é o principal exportador e importador do mundo, tendo ultrapassado até mesmo os EUA (OMC, 2018). No que diz respeito especificamente ao comércio marítimo, a China também domina os indicadores, já que só no Mar da China do Sul - região com maior fluxo de comércio marítimo do mundo - os chineses também são os principais exportadores e importadores (CSIS, 2019b). Esse imperativo econômico, associado a um maior ímpeto para a participação em questões globais, levou a China a delinear determinadas estratégias político/econômicas a fim de assegurar seus objetivos (WANG, 2019).

Uma dessas importantes iniciativas é o estabelecimento da Rota da Seda Marítima, uma política que está inserida dentro da iniciativa Belt and Road, cujo objetivo é facilitar o trânsito marítimo e tornar mais seguras as linhas de comunicação marítimas (SLCO’s) que ligam o Golfo de Áden ao Oceano Índico e esse último ao Estreito de Malacca. A iniciativa inclui a construção de portos e instalações em Myanmar no Sri Lanka, nas Maldivas, Paquistão e até mesmo uma base militar do Djibuti (SZECHENYI et. al, 2018). A construção e expansão de uma marinha capaz de projeção força além-mar, serviria, dentre outras coisas, para defender os interesses chineses nessas SLCO's, as instalações portuárias do país e garantir o fluxo de bens da China e para a China. Missões antipirataria em águas distantes, missões contra bloqueio naval e o emprego rápido de forças desembarcadas pelo mar dependem ativamente de uma Blue Water Navy.

Se os interesses chineses estão além-mar, por que a China também busca construir forças navais costeiras, sistemas de $\mathrm{A} 2 / \mathrm{AD}$ e até mesmo forças não convencionais como milícias marítimas? Isso acontece pois, ao contrário dos EUA que não possuem potências rivais em suas águas próximas, a China tem de lidar com a constante presença de forças navais em suas proximidades costeiras. Desde as crises do Estreito de Taiwan nos anos 1990 até as atuais operações de navegação livre conduzidas, sobretudo pela marinha estadunidense, Pequim deseja afastar eventuais potências hostis de sua costa (PANDA, 2020). Em um White Paper de segurança e defesa publicado pela China em 2019, as disputas territoriais marítimas no Mar da China do Sul e do Leste foram elevadas a um status semelhante às questões de integração territorial de Taiwan, do Tibete e da província de Xinjiang (CHINA, 2019).

Para garantir efetivamente a capacidade de projetar sua força naval e assegurar os seus interesses além-mar, a China deve, primeiramente, acertar os ponteiros a nível regional e firmar uma posição sólida no Pacífico Asiático. De acordo com as autoridades chinesas, a soberania do país sobre toda a área dentro da Nine Dash Line - um território que compreende quase todo o Mar da China do Sul - não só é direito da China, como condição necessária para garantir os interesses de segurança do país (CHINA, 2019). É em função dessas questões e demandas que a China precisa de instrumentos de $\mathrm{A} 2 / \mathrm{AD}$ e law enforcement - que vão desde mísseis balísticos antinavio até milícias marítimas - para negar a outrem a capacidade de agir em suas águas próximas ao mesmo tempo que estabelece e fixa sua posição regional. 
Segundo alguns autores, como Holmes e Yoshihara (2006), a estratégia naval chinesa teria nas ideias de Alfred Thayer Mahan (1918) sua principal fonte de inspiração. A China, consciente do fato de que é uma potência comercial marítima, procuraria construir uma volumosa frota de navios principais a fim de obter a capacidade de atingir o comando do mar, protegendo suas linhas de comunicação marítimas e garantindo dominância no Pacífico Asiático. Como uma boa potência naval, a China iria buscar o comando do mar construindo uma força naval grande e capaz de impor aos respectivos adversários uma derrota decisiva, a ponto de impedir que eles possam utilizar o mar para seus respectivos propósitos (MAHAN, 1918).

Embora seja difícil negar que as ideias de Mahan tenham certa penetração na estratégia naval chinesa - assim como em qualquer país -, também é complicado afirmar que o que a China busca é a capacidade de obter o comando do mar estritamente como defendido pelo autor. Ao construir uma marinha com capacidade de projeção de força além-mar a fim de salvaguardar sua Rota da Seda Marítima e ao fortalecer sua capacidade A2/AD para limitar a ação de potências hostis em águas próximas, a China está buscando garantir o uso do mar para seus propósitos e impedir que outros a impeçam de fazê-lo. Essa visão do poder marítimo se assemelha mais ao ponto de vista defendido por Julian Corbett (1994), que enxerga o poder marítimo como elemento fundamental, mas não suficiente, para se obter vantagem estratégica sobre os adversários.

No final, a importância do mar e das forças navais para a China pode ser, de maneira mais ampla, reduzida a uma palavra: Fluxos! Em tempos de paz, esses fluxos sustentam, por meio do comércio marítimo, as atividades econômicas do país e o bem-estar da população. Em tempos de guerra, esses mesmos fluxos são usados para sustentar, por meio do transporte de tropas e suprimentos, a capacidade de combate em terra. Não é em função de uma característica especial das forças navais ou qualquer tipo de singularidade do poder marítimo que levou e tem levado a China a expandir o seu poder naval. Os chineses têm se lançado ao mar por necessidade. Necessidade essa que advém dos imperativos de ser uma potência comercial marítima e uma grande potência em ascensão.

\section{CONSIDERAÇÕES FINAIS}

A China está incrementando rapidamente o seu poderio naval, podendo ser considerada uma das principais potências marítimas do mundo. Os chineses têm lançado ao mar, em um ritmo impressionante, uma grande quantidade de modernas embarcações, que vão desde navios de patrulha costeira, passando por submarinos nucleares, indo até porta-aviões. Forças não convencionais de law enforcement, como as milícias marítimas, e a sua capacidade A2/AD também são elementos fundamentais da expansão naval da China. Todo esse processo de expansão e modernização naval serve, principalmente, aos propósitos políticos e estratégicos chineses, tendo 
em vista o crescente papel do país no comércio marítimo internacional e a expansão dos interesses geoestratégicos da China para além-mar.

Por fim, a recente e rápida ascensão da China ao status de potência naval deixa algumas questões que merecem atenção em função dos seus possíveis desdobramentos. Tendo em vista o fato de que boa parte das forças navais chinesas serem recentes e ainda existir certa dúvida sobre sua real capacidade, estaria a PLAN disposta a testá-las? Se sim, em quais tipos de operação? Taiwan seria um bom primeiro teste? Que tipo de reações essa expansão naval chinesa pode desencadear? Será a Índia mais um país a entrar de vez no tabuleiro naval do Pacífico Asiático? O Japão pode vir a abandonar suas autorrestrições? Como o choque entre as forças navais dos Estados Unidos e da China será manejado entre os dois países? Um confronto naval entre as duas potências é inevitável? Por isso, a expansão naval chinesa, bem como a ascensão do país asiático de maneira mais ampla, deve ser tratada com muita atenção e cuidado em função das possíveis consequências de larga escala que ela pode trazer para a política internacional.

\footnotetext{
*Artigo recebido em 04 de janeiro de 2021, aprovado em 05 de março de 2021.
}

\section{REFERÊNCIAS}

AMTI. A Constructive Year for Chinese Base Building. Asia Maritime Transparence Initiative. 2017. Disponível em: <https://amti.csis.org/constructive-year-chinese-building/>. Acesso em 07 mar. 2021.

BELO, Dani. Conflict in the absence of war: a comparative analysis of China and Russia engagement in gray zone conflicts. Canadian Foreign Policy Journal, vol. 26, n. 1, p.(73-91), 2020.

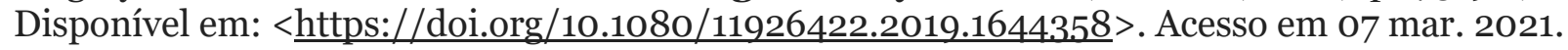

BITZINGER, Richard A; CHAR, James. Reshaping the Chinese Military: the PLA's Roles and Missions in the Xi Jinping Era. New York: Routledge, 2019.

BROOKES, Peter. The INF Treaty-What It Means for the U.S., Russia, and China Today. The Heritage Foundation. 2019. Disponível em: <https://www.heritage.org/armscontrol/report/the-inf-treaty-what-it-means-the-us-russia-and-china-today $>$. Acesso em $07 \mathrm{mar}$. 2021.

CHAN, Minnie. As overseas ambitions expand, China plans 400 per cent increase to marine corps numbers, sources say. South China Morning Post. 2017. Disponível em: <https://www.scmp.com/news/china/diplomacy-defence/article/2078245/overseas-ambitionsexpand-china-plans-40opcincrease?utm source=Sailthru\&utm medium=email\&utm campaign=EBB\%2002.14.2017\&utm term=Editorial\%20-\%20Early\%20Bird\%20Brief >. Acesso em 07 mar. 2021.

CHILDS, Nick; WALDWYN, Tom. China's naval shipbuilding: delivering on its ambition in a big way.International Institute of Strategic Studies: Military Balance Blog. 2018. Disponível em: 
<https://www.iiss.org/blogs/military-balance/2018/05/china-naval-shipbuilding >. Acesso em 07 mar. 2021.

CHINA. China's National Defense in the New Era. The State Council of People's Republic of China. 2019.

CIA. The World Factbook: China. Central Intelligence Agency. 2020. Disponível em: $<$ https://www.cia.gov/library/publications/the-world-factbook/geos/ch.html >. Acesso em 07 mar. 2021.

CORBETT, Julian. Some Principles of Maritime Strategy. Annapolis: Naval Institute Press, 1994.

CSIS. How is China modernizing its navy?. Center for Strategic and International Studies: China Power Project. 2020. Disponível em: <https://chinapower.csis.org/china-navalmodernization/\# easy-footnote-bottom-3-4084>. Acesso em 07 mar. 2021.

CSIS. How does China's first aircraft carrier stack up?. Center for Strategic and International Studies: China Power Project. 2020b. Disponível em: <https://chinapower.csis.org/aircraftcarrier/>. Acesso em 07 mar. 2021.

CSIS. YJ-18.Center for Strategic and International Studies: Missile Threat. 2020c. Disponível em: <https://missilethreat.csis.org/missile/yj-18/>. Acesso em 07 mar. 2021.

CSIS. DF-21 (Dong Feng-21 / CSS-5). Center for Strategic and International Studies: Missile Threat. 2020d. Disponível em: < https://missilethreat.csis.org/missile/df-21/>. Acesso em 07 mar. 2021.

CSIS. What do we know (so far) about China's second aircraft carrier? Center for Strategic and International Studies: China Power Project. 2019. Disponível em: <https://chinapower.csis.org/china-aircraft-carrier-type-001a/> . Acesso em 07 mar. 2021.

ERICKSON, Andrew S. Chinese Anti-Ship Ballistic Missile (ASBM) Development: Drivers, Trajectories and Strategic Implications. Washington DC: The Jamestown Foundation, 2013.

GADY, Franz-Stefan. China Launches New Type o54A Guided-Missile Stealth Frigate. The Diplomat. 2017. Disponível em: <https://thediplomat.com/2017/12/china-launches-new-type054a-guided-missile-stealth-frigate/>. Acesso em 07 mar. 2021.

GLYNN, Michael. Airborne Over the Horizon Targeting Options to Enable Distributed Lethality. Center for International Maritime Security. 2015. Disponível em: <http://cimsec.org/airborne-horizon-targeting-options-enable-distributed-lethality/17301>. Acesso em: Acesso em 07 mar. 2021.

GOLDRICK, James. Grey Zone Operations and the Maritime Domain. Australian Strategic Policy Institute - Special Report. 2018. Disponível em: <https://s3-ap-southeast2.amazonaws.com/ad-aspi/201810/SR\%20131\%20Grey\%20zone\%20operations.pdf?V7EA5lJx4eMZPm7rrgsnXkXq8Q46O.Wg>. Acesso em 07 mar. 2021.

GORMLEY, Dennis M; ERICKSON, Andrew S; YUAN, Jingdong. A Low-Visibility Force Multiplier: Assessing China's Cruise Missile Ambitions. Washington D.C: National Defesne University Press, 2014.

HEILMANN, Sebastian. China's Political System. Boulder: Rowman \& Littlefield, 2017. 
HOLMES, James R; YOSHIHARA, Toshi. The Influence of Mahan upon China's Maritime Strategy, Comparative Strategy, vol. 24, n. 1, p. $(23-$ 51), 2006. Disponível em: $<\underline{10.1080 / 01495930590929663>}$. Acesso em 07 mar. 2021.

IISS. Chapter Six: Asia. The Military Balance, vol. 120, n. 1, p. (220-323), 2020. Disponível em: $<10.1080 / 04597222.2020 .1707967>$. Acesso em 07 mar. 2021.

IISS. Chapter Eight: Latin America and the Caribbean. The Military Balance, vol. 120, n.1, p. (388 - 443), 2020. Disponível em: < 10.1080/04597222.2020.1707970>. Acesso em 07 mar. 2021.

KENNEDY, Conor M; ERICKSON, Andrew S. China's Third Sea Force, The People's Armed Force Maritime Militia Tethered to the PLA. China Maritime Studies Institutes - China Maritime Report No 1.

LEE, Sanguk. China's 'Three Warfares': Origins, Applications, and Organizations. Journal of Strategic Studies, vol. 37, n. 2, p. 198-221. 2014. Disponível em: $<$ https://doi.org/10.1080/01402390.2013.870071>. Acesso em 07 mar. 2021.

LEWIS, Jeffrey. Paper Tigers: China’s Nuclear Posture. Londres: IISS. 2014.

LIANG, Qiao. XIANGSUI, Wang. Unrestricted Warfare. Beijing: PLA Literature and Arts Publishing House, 1999.

Mahan, Alfred T. The Influence of Sea Power Upon History, 1690-1783. Boston: Little Brown, 1918.

MASTRO, Oriana Skylar. China's Anti-access-Area Denial (A2/AD) Capabilities: Is American Rebalancing Enough?. In: BROOKS, Jason. NATTER III, William H. American Strategy and Purpose: Reflections on Foreign Policy and National Security in an Era of Change. Washington D.C: CENSA, 2014. p. 118-140.

MACHAFFIE, James. The geopolitical Roots of China's naval modernisation. Australian Journal of Maritime \& Ocean Affairs, vol. 12, n. 1, p. (1- 15), 2020. Disponível em:

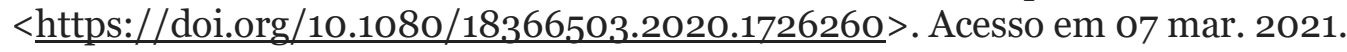

MORRIS, Lyle J. Blunt Defenders of Sovereignty - The Rise of Coast Guards in East and Southeast Asia. Naval War College Review, vol. 70, n. 2, p. (75-112), 2017. Disponível em: <https://digitalcommons.usnwc.edu/nwc-review/vol7o/iss2/5>. Acesso em 07 mar. 2021.

ONI. China: Naval Construction Trends vis-à-vis U.S. Navy Shipbuilding Plans, 20202030. Office of Naval Intelligence. 2020. Disponível em: <https://fas.org/irp/agency/oni/plantrends.pdf $>$. Acesso em 07 mar. 2021.

O’ROURKE, Ronald. China Naval Modernization: Implications for U.S. Navy CapabilitiesBackground and Issues for Congress. Congressional Research Service. 2020.

PANDA, Ankit. US Conducts Freedom of Navigation Operation Near China-Held Features in Spratlys. The Diplomat. 2020. Disponível em: <https://thediplomat.com/2020/07/us-conducts-freedom-of-navigation-operation-near-chinaheld-features-in-spratlys/>. Acesso em 07 mar. 2021.

SZECHENYI, Nicholas et al. China's Maritime Silk Road: Strategic and Economic Implications for the Indo-Pacific Region. Center for Strategic and International Studies. 2028. Disponível em: $<$ https://csis-website-prod.s3.amazonaws.com/s3fspublic/publication/180404 Szechenyi ChinaMaritimeSilkRoad.pdf?yZSpudmFyARwcHuJnNx3 metxXnEksVX3 $>$. Acesso em 07 mar. 2021. 
UNCTAD. International Data On Shipbuilding. United Nations Conference on Trade and Development. 2018. Disponível em: $<$ https://unctadstat.unctad.org/wds/TableViewer/tableView.aspx >. Acesso em 07 mar. 2021.

US DEPARTAMENT OF DEFENSE. Annual Report to Congress: Military and Security Developments Involving the People's Republic of China 2019. Departament of Defense of United States of America. 2019. Disponível em: <https://media.defense.gov/2019/May/02/2002127082/1/-1/1/2019 CHINA MILITARY POWER REPORT.pdf>. Acesso em 07 mar. 2021.

WANG, Jianwei. Xi Jinping's 'Major Country Diplomacy:' A Paradigm Shift? Journal of Contemporary China, vol. 28, n. 115, p. (15 - 30), 2019. Disponível em: < https://doi.org/10.1080/10670564.2018.1497907>. Acesso em 07 mar. 2021.

WTO. Global perspectives: Who are the Leading Players?. World Trade Organization. 2018. Disponível em: <https://www.wto.org/english/res_e/statis_e/wts2018_e/wts2018chaptero5_e.pdf>. Acesso em 07 mar. 2021. 